\title{
Hemşirelik Bölümü Öğrencilerinde Anksiyete Durumunun Kariyer Kararı Yetkinlik Beklentisine Etkisinin Belirlenmesi
}

\author{
DOI: 10.26466/opus.581800
}

\begin{abstract}
*
Meltem Kürtüncü* - Hicran Yıldız**

* Doç. Dr, Zonguldak Bülent Ecevit Üniversitesi,Sağlık Bilimleri Fakültesi, Zonguldak / Türkiye E-Posta: meltemipekkurtuncu@gmail.com ORCID: $\quad$ 0000-0003-3061-5236

** Doç. Dr, Uludağ Üniversitesi Sağllk Bilimleri Fakültesi, Bursa / Türkiye E-Posta: hicran yildiz@yahoo.com ORCID: *** Arş.Gör., Zonguldak Bülent Ecevit Üniversitesi,Sağlık Bilimleri Fakültesi, Zonguldak /Türkiye E-Posta: aylinkurt67@gmail.com ORCID: $\underline{0000-0002-5521-0828}$

\section{Öz}

Araştırma, hemşirelik bölümü öğrencilerinde anksiyete durumunun kariyer kararı yetkinlik beklentisine etkisinin belirlenmesi amacıyla yapılmıştır. Tanımlayıcı ve analitik nitelikteki araştırmanın örneklemini 2017-2018 eğitim öğretim yılında hemşirelik bölümü 3.ve 4. simffta öğrenim gören 300 öğrenci oluşturmuştur. Veriler "Anket Formu", "Sürekli ve Durumluk Anksiyete Ölçeği" ve "Kariyer Kararı Yetkinlik Beklentisi Ölçeği" ile elde edilmiştir. Veriler; yüzdelikler, ortalamalar, $t$ testi, Mann Whitney U testi, Kruskal Wallis testi, One-way Anova testi, Pearson korelasyon testi ve Spearman korelasyon testi kullanılarak değerlendirilmiştir. Ö̆grencilerin yaş ortalaması $22,03 \pm 1,46$ ve \% 77,7'si kadındır. Ö̆grencilerin durumluk anksiyete puanı ortalaması $36,48 \pm 6,86$, sürekli anksiyete $39,24 \pm 7,48$ ve kariyer karar yetkinlik beklentisi puan $94,88 \pm 15,80$ 'dir. Öğrencilerin durumluk ve sürekli anksiyete puanları ile kariyer kararı yetkinlik beklentisi puanı arasında anlamlı ilişki saptanmıştır $(p<, 05)$. Öğrencilerin durumluk anksiyete puanında yaş, cinsiyet ve sinıfa göre anlamlı ilişkilere rastlanmıştır $(p<, 05)$. Öğrencilerin durumluk ve sürekli anksiyete düzeyi kariyer kararı yetkinlik beklentisini etkilemektedir.Öğrencilerde anksiyeteye neden olan faktörlerin belirlenmesine ve anksiyete ile kariyer yetkinlik beklentisi arasındaki ilişkiyi tanımlamaya yönelik daha fazla sayıda çalışma yapılması önerilmektedir.
\end{abstract}

Anahtar Kelimeler: Anksiyet,; Kariyer, Yetkinlik, Öğrenci 


\title{
Determining the Effect of Anxiety Status on Career Decision Self Efficacy in Nursing Students
}

\begin{abstract}
This study aimed to determine the effect of anxiety on nursing students' career decision competence expectancy. The sample of the descriptive and analytical study consisted of 300 students in the $3 \mathrm{rd}$ and 4th year nursing department in 2017-2018. The data were obtained by "Questionnaire Form", "State of Anxiety and State Anxiety Scale" and "Career Decision Competency Expectation Scale". Data was evaluated by percentages, averages, $t$ test, Mann Whitney $U$, Kruskal Wallis, One-way Anova tests, Pearson and Spearman correlation test. The mean age of the students was 22,03 $\pm 1,46$ and $77,7 \%$ were female. The mean score of state anxiety score of the students is $36,48 \pm 6,86$, continuous anxiety is 39,24 $\pm 7,48$ and career decision is $94,88 \pm 15,80$. A significant relationship was found between the state and trait anxiety scores of the students and the career expectancy score $(p<, 05)$. Significant correlations were found in state anxiety scores of the students according to age, gender and class $(p<, 05)$. The level of state and trait anxiety of the students affected the career expectancy. It is suggested that more studies should be done to identify the factors that cause anxiety and the relationship between anxiety and career expectancy expectations.
\end{abstract}

Keywords: Anxiety, Career, Competence, Student 


\section{Giriş}

Kariyer yapma ve kariyer sürecini şekillendirme gibi konularda alınan bütün kararlar bireylerin tüm hayatını etkileyeceği için en önemli kararlardan biridir. Bu karar, gelecekte bireylerin mesleki performansını, iş doyumunu ve hayata dair mutluluğunu etkileyecektir. Çünkü kariyeri hakkındaki yanlış seçim yapan birey, tüm hayatı boyunca istemediği ve sevmediği bir süreç içerisinde kalmaya bağlı sürekli anksiyete ve strese yaşayabilmekte ve bu durum da mesleki tükenmişliğe sebep olabilmektedir (Jung, Jeong ve Yoo, 2014; Çatak ve Bahçecik, 2015). Bu nedenle kariyere karar verme, bireyler için stres yaratan bir süreç haline gelebilmektedir.

Günümüzde kariyer kararı bireylerin üniversite son sınıfta öğrencilikten iş hayatına geçiş aşamasında vermek zorunda kaldıkları bir karardır (Jung ve diğ., 2014; Kim, 2016). Çünkü öğrencilikten iş hayatına geçiş aşamasında olan üniversite son sınıf öğrencilerinin mesleği ve ilgi alanları doğrultusunda önündeki kariyer seçenekleri ile ilgili bilgi toplama, onları değerlendirme ve geleceğe ilişkin plan yapması gerekmektedir (Kocaman ve Yürümezoğlu, 2015). Mezun olduktan sonra ne yapacağını bilememe, özellikle mezuniyeti yaklaşan hemşirelik öğrencilerinin kariyerlerine ilişkin kaygı sebeplerinden biridir (Kılıç, 2018). Ayrıca öğrencilerin eğitim hayatı boyunca yaşadıkları olumsuz deneyimler de anksiyete sebebi olmakta ve dolasıyla kariyer düşüncesini, sürecini ve geleceğe dair beklentilerini de olumsuz etkilemektedir (Sevinç ve Özdemir, 2017; Taslak ve Iş1kay, 2015).

Ülkemizde yapılan araştırmalarda cinsiyet, sınıf, yaş ve maddi durum gibi demografik özellikler ve mesleği isteyerek ya da başka birinin yönlendirmesi ile seçme, iş bulma kaygısı gibi faktörlerin ele alınmaktadır (Özdelikara, Ağaçdiken ve Aydın, 2016; Özdemir ve Şahin, 2016; Temel, Bilgic ve Celikkalp, 2018). Ayrıca bu araştırmaların çoğunlukla hemşirelik birinci sınıf öğrencileri ile yapıldığı ve hemşirelik mesleğini seçme nedenlerinin araştırıldığı araştırmalar olduğu görülmektedir (Özdelikara ve diğ., 2016; Özdemir ve Şahin, 2016). Oysaki üniversite üçüncü ve son sınıf öğrencisi olmak iş hayatına atılmak için son aşamadır ve öğrencilerin geleceğe dair kaygılarını daha yoğun olarak hissettikleri dönemlerdir (Choi ve Jung, 2018; Kim ve Lee, 2015). Kayg1 ve stres düzeyinin yüksek olmas1 
sağliklı düşünmeyi olumsuz etkileyeceği için bireylerin yanlış karar vermesine ve kariyeri ile ilgili umutsuzluğa kapılmasına neden olabilmektedir (Gümüştekin ve Gültekin, 2009). Ülkemizde yapılan araştırmalara bakıldığında, hemşirelik öğrencilerinin anksiyete durumlarının kariyer kararı üzerindeki etkisini inceleyen araştırmaya rastlanılmamıştır. Bu nedenle bu araştırmada hemşirelik bölümü öğrencilerinde anksiyete durumunun kariyer kararı yetkinlik beklentisi üzerinde etkisini belirmek amaçlanmıştır.

Bu bağlamda şu sorulara cevaplar aranmıştır:

- Hemşirelik bölümü öğrencilerinde anksiyete durumunun kariyer kararı yetkinlik beklentisi ne düzeydedir?

- Hemşirelik bölümü öğrencilerinin kariyer kararı yetkinlik beklentisi sosyodemografik özelliklerine göre farklllık göstermekte midir?

- Hemşirelik bölümü öğrencilerinde anksiyete durumunun kariyer kararı yetkinlik beklentisi arasında ilişki var mıdır?

\section{Yöntem}

\section{Araştırmanın Modeli}

Araştırmanın amacı hemşirelik bölümü öğrencilerinde anksiyete durumunun kariyer kararı yetkinlik beklentisi üzerinde etkisini yani arasındaki ilişkiyi belirlemek olması nedeniyle ilişkisel tarama modeli kullanılmıştır. İlişkisel tarama modeli, birden fazla sayıdaki değişken arasında değişimi ve/veya derecesini tespit etmeyi amaçlayan bir modeldir (Çaparlar ve Dönmez, 2016; Karasar, 2013).

\section{Araştırmanın Evreni ve Örneklemi}

Araştırmanın evrenini Zonguldak Bülent Ecevit Üniversitasi Sağlık Bilimleri Fakültesi'nde 2017-2018 eğitim öğretim yılında hemşirelik bölümü 3. ve 4. sınıfta öğrenim gören tüm öğrenciler, örneklemini ise bu bireyler arasından çalışmaya katılmayı kabul eden evrenin \%95'ini oluşturan 300 öğrenci oluşturmuştur. 


\section{Veri Toplama Araçlan}

Veriler "Anket Formu”, "Sürekli ve Durumluk Anksiyete Ölçeği” ve “Kariyer Kararı Yetkinlik Beklentisi Ölçeği" ile elde edilmiştir.

Anket Formu: Araştırmacılar tarafından hazırlanan öğrencilerin yaş, cinsiyet, sınıf, gelir düzeyi, aile yapısı, anne-baba eğitim ve çalışma durumları gibi sosyodemografik özelliklerinin sorgulandığı formdur.

Sürekli ve Durumluk Anksiyete Ölçeği: Öner ve Le Compte (1983) tarafından Türk kültürüne uyarlanan, topalm kırk sorudan oluşan DurumlukSürekli Anksiyete Ölçeği; Durumluk Ankisyete Ölçeği ile Sürekli Anksiyete Ölçeği olmak üzere iki alt ölçekten oluşmaktadır. Durumluk Anksiyete Ölçeği, bireylerin belirli bir anda belirli koşullarda kendisini nasıl hissettiğini betimlemesini, içinde bulunduğu duruma ilişkin duygularını dikkate alarak maddeleri cevaplamasını gerektirir. Sürekli Anksiyete Ölçeği ise birey genel olarak kendisini nasıl hissettiğini belirtmektedir. Durumluk Anksiyete Ölçeği, maddeleri; (1) hiç, (2) biraz, (3) çok, (4) tamamıla gibi şeklindeki derecelendirme şeklinde cevaplandırılmaktadır. Sürekli Anksiyete Ölçeğinin maddeleri ise sıklık derecesine göre; (1) hemen hiçbir zaman, (2) bazen, (3) çok zaman ve (4) hemen her zaman şeklinde cevaplandirılır. Olumlu ifadeler olumsuz duyguları, olumsuz ifadeler olumlu duyguları dile getirmektedir. Durumluk Anksiyete Envanteri'ndeki olumsuz ifadeler 1, 2, 5, 8, 10, 11, 15, 16, 19 ve 20. madde; Sürekli Anksiyete Envanteri' deki olumsuz ifadeler ise 21, 26, 27, 30, 33, 36 ve 39. maddelerdir. Olumlu ve olumsuz ifadelerin ayrı, ayrı toplam ağırlıkları hesaplanmakta, ters ifadelerin toplamı doğrudan ifadelerin toplamından çıkarılmaktadır. Elde edilen puana önceden belirlenmiş ve değişmeyen bir değer eklenmektedir. Durumluk Anksiyete Envanteri için bu değişmeyen değer 50, Sürekli Anksiyete Envanteri için 35'dir. En son elde edilen değer bireyin anksiyete değeridir. Her iki olcekten elde edilen puanlar 20 ile 80 puan arasında değişmektedir. Yüksek puanlar bireyin anksiyete düzeyinin yüksekliğini göstermektedir (Önel ve LeCompte, 1983). 
Kariyer Karan Yetkinlik Beklentisi Ölçeği: Betz, Klein ve Taylor (1996) tarafından geliştirilen Kariyer Kararı Yetkinlik Beklentisi Ölçeği (KKYBÖ), Işık (2010) tarafından Türk kültürüne uyarlanmıştır. Toplam 25 maddeden oluşan beşli likert tipi bir ölçektir (Hiç Güvenmiyorum-1'den Çok Güveniyorum-5'e doğru derecelendirilmektedir). KKYBÖ'nün Cronbach Alfa katsayısı 0,88 olarak tespit edildiği bildirilmektedir. Ölçekten alınan yüksek puanlar kariyer kararı yetkinlik beklentisinin yüksek düzeyde olduğunu ifade etmektedir (Işık, 2010).

\section{Araştırmanın Uygulanması}

Çalışma, araştırmacılar tarafından Ocak-Mayıs 2018 tarihleri arasında Zonguldak Bülent Ecevit Üniversitesi Sağlık Bilimleri Fakültesi Hemşirelik Bölümü 3.ve 4.sınıfa devam eden ve araştırmaya katılmaya gönüllü öğrenciler ile yapılmıştır. Araştırmanın amacı ve önemi hakkında bilgi verildikten sonra yazılı onam alınmıştır. Veriler öğrencilerin derslerinin olmadığ1 uygun oldukları zamanlarda araştırmacılar tarafından, yüz yüze görüşme tekniği ile toplanmıştır. Soruların cevaplanması yaklaşık 20 dakika sürmüştür.

\section{Verilerin Değerlendirilmesi}

Verilerin değerlendirilmesinde SPSS 22,0 kullanılmıştır. Verilerin normal dağılımdan gelip gelmediğine bakmak için Kolmogrov Smirnov Testi kullanılmıştır. Tanımlayıcı istatistikler için yüzde, ortalama, standart sapma kullanılmıştır. Gruplar arasındaki fark incelenirken t testi, Mann Whitney U testi, Kruskal Wallis testi ve One-way Anova testi; ilişki bakılırken Pearson korelasyon testi ve Spearman korelasyon testi kullanılmıştır. Sonuçlar \%95 güven aralığında değerlendirilmiştir.

\section{Bulgular}

Yaş ortalaması 22,03 $\pm 1,46$ olan öğrencilerin \%77,7'i kadındır. Öğrencilerin $\% 60,7$ 'si 3.sınıf ve \%39,3'ü 4.sınıf öğrencisi ve annelerinin yaş ortalaması $47,35 \pm 5,42$, babalarının $51.29 \pm 5.79$ idi. Öğrencilerin \%60'ının annesinin ve $\% 42$ 'sinin babasının ilkokul mezunu, \%13,7'sinin annesinin ve $\% 63,7^{\prime} \operatorname{sinin}$ 
babasının tam zamanlı çalışıyordu ve \%91,3'ünün anne ve babası birlikte ve \%34'ünün ailesinin aylık geliri 2000-3000 TL idi. \%43,3'ü birinci çocuk olduğu tespit edilen öğrencilerin \%30'u 2, \%30'u 3, \%19,7'si 4 kardeş ve $\% 43,3$ 'ü birinci çocuktu.

Tablo 1. Öğrencilerin sürekli ve durumluk anksiyete ölçeği ve kariyer karar yetkinlik beklentisi ölçeği puanlarının dağılımı $(\mathrm{N}=300)$

\begin{tabular}{llll}
\hline Değişken adı & & OrtıSS & Min-Mak \\
\hline Anksiyete & Durumluk Anksiyete & $36,48 \pm 6,86$ & $10-63$ \\
& Sürekli Anksiyete & $39,24 \pm 7,48$ & $12-64$ \\
Kariyer kararı yetkinlik beklentisi & Toplam & $94,88 \pm 15,80$ & $25-139$ \\
\hline
\end{tabular}

Öğrencilerin durumluk anksiyete puanı ortalaması 36,48 $\pm 6,86$, sürekli anksiyete $39,24 \pm 7,48$ ve kariyer kararı yetkinlik beklentisi puanı $94,88 \pm 15,80$ ' dir (Tablo 1).

Tablo 2. Durumluk ve sürekli anksiyete puanları ile kariyer kararn yetkinlik beklentisi puanı arasındaki ilişki $(\mathrm{N}=300)$

\begin{tabular}{lll}
\hline Değişken adı & Durumluk Anksiyete & Sürekli Anksiyete \\
\hline Kariyer kararı yetkinlik beklentisi ${ }^{*}$ & $\mathrm{r}=0,238 ;{ }^{*} \mathrm{p}=, \mathbf{0 0 0}$ & $\mathrm{r}=0,141 ;{ }^{*} \mathrm{p}=, \mathbf{0 1 5}$ \\
\hline
\end{tabular}

* Pearson korelasyon testi ${ }^{\Psi} p<, 05$

Öğrencilerin durumluk ve sürekli anksiyete puanları ile kariyer kararı yetkinlik beklentisi puanı arasındaki ilişki incelendiğinde, öğrencilerin kariyer kararı yetkinlik beklentisi durumluk ve sürekli anksiyete düzeyleri de artmaktadır ( $\mathrm{p}<, 05)$ (Tablo 2).

Araştırmaya katılan öğrencilerin bazı sosyodemografik özelliklerine göre Durumluk ve Sürekli anksiyete puanları ile kariyer kararı yetkinlik beklentisi puan ortalamalarındaki farklılık incelendiğinde yapılan ileri analizde erkek öğrencilerin kız öğrencilerden ve 4.sınıf öğrencilerinin 3.s1nıf öğrencilerinden anlamlı şekilde durumluluk anksiyete düzeylerinin daha yüksek olduğu belirlenmiştir $(\mathrm{p}<, 05)$ (Tablo 3).

Öğrencilerin durumluk ve sürekli anksiyete puanları ile kariyer kararı yetkinlik beklentisi puanlarının bazı sosyodemografik özellikleri ile ilişkisi incelendiğinde, öğrencilerin yaşının arttıkça durumluk anksiyete düzeylerinin de arttığı tespit edilmiştir $(\mathrm{p}<, 05)$. 
Tablo 3. Durumluk ve sürekli anksiyete puanları ile kariyer kararn yetkinlik beklentisi puanlarının öğrencilerin sosyodemografik özelliklerine göre farklılıkları $(\mathrm{N}=300)$

\begin{tabular}{|c|c|c|c|c|}
\hline \multicolumn{2}{|l|}{ Özellikler } & $\begin{array}{l}\text { Kariyer kararı } \\
\text { yetkinlik beklentisi }\end{array}$ & \multirow{2}{*}{$\begin{array}{l}\begin{array}{l}\text { Durumluk } \\
\text { Anksiyete }\end{array} \\
35,86 \pm 5,93 \\
\end{array}$} & \multirow{2}{*}{$\begin{array}{l}\begin{array}{l}\text { Sürekli } \\
\text { Anksiyete }\end{array} \\
39,24 \pm 6,72\end{array}$} \\
\hline Cinsiyet* & Kadın & $95,65 \pm 15,37$ & & \\
\hline & Erkek & $92,19 \pm 17,04$ & $38,62 \pm 9,14$ & $39,22 \pm 9,72$ \\
\hline & Anlamlılık & $\mathrm{t}=1,583 ; \mathrm{p}=, 115$ & $\mathrm{t}=-2,336 ;{ }^{\mathrm{x}} \mathrm{p}=, 022$ & $\mathrm{t}=0,016 ; \mathrm{p}=, 987$ \\
\hline & 3.sinif & $95,48 \pm 14,62$ & $35,70 \pm 5,86$ & $38,54 \pm 6,43$ \\
\hline \multirow[t]{5}{*}{ Sinıf** } & 4.sinif & $93,91 \pm 17,58$ & $37,73 \pm 8,09$ & $40,35 \pm 8,82$ \\
\hline & \multirow{2}{*}{ Anlamlılık } & $\mathrm{U}=10112,000$ & $\mathrm{U}=9066,000$ & $\mathrm{U}=9441,000$ \\
\hline & & $\mathrm{Z}=-0,720 ; \mathrm{p}=, 472$ & $Z=-2,155 ;{ }^{x} p=0,031$ & $Z=-1,640 ; p=, 101$ \\
\hline & Anne ve Baba & $94,71 \pm 16,49$ & $36,94 \pm 7,36$ & $38,97 \pm 7,99$ \\
\hline & Anne & $99,09 \pm 15,02$ & $36,63 \pm 4,61$ & $38,18 \pm 7,44$ \\
\hline Birlikte & Baba & $88,00 \pm 9,89$ & $40,50 \pm 4,94$ & $48,50 \pm 2,12$ \\
\hline \multirow{5}{*}{ Yaşadığı Kişi ${ }^{* * *}$} & Akrabaları & $93,00 \pm 15,24$ & $33,20 \pm 2,16$ & $38,20 \pm 3,96$ \\
\hline & Arkadaşları /Yurt & $94,87 \pm 15,36$ & $36,07 \pm 6,60$ & $39,48 \pm 7,07$ \\
\hline & Anlamlılık & $\mathrm{KW}=1,490 ; \mathrm{p}=, 828$ & $\mathrm{KW}=4,439 ; \mathrm{p}=0,350$ & $\mathrm{KW}=4,783 ; \mathrm{p}=, 310$ \\
\hline & $500-1000$ & $89,38 \pm 19,27$ & $34,61 \pm 8,46$ & $39,04 \pm 8,44$ \\
\hline & $1000-2000$ & $94,23 \pm 13,60$ & $36,16 \pm 6,57$ & $39,67 \pm 7,87$ \\
\hline Ailenin & $2000-3000$ & $95,90 \pm 15,24$ & $36,60 \pm 6,44$ & $38,48 \pm 6,69$ \\
\hline Gelir & $3000-4000$ & $92,78 \pm 18,23$ & $36,02 \pm 6,20$ & $38,82 \pm 6,68$ \\
\hline \multirow[t]{3}{*}{ Düzeyi ${ }^{* * * *}$} & 4000-Üzeri & $100,05 \pm 16,06$ & $38,79 \pm 8,40$ & $41,05 \pm 9,05$ \\
\hline & Anlamlılık & $\mathrm{F}=1,939 ; \mathrm{p}=, 104$ & $\mathrm{~F}=1,476 ; \mathrm{p}=0,209$ & $\mathrm{~F}=0,885 ; \mathrm{p}=, 473$ \\
\hline & Anne Baba Birlikte & $94,87 \pm 15,87$ & $36,53 \pm 6,89$ & $38,97 \pm 7,48$ \\
\hline \multirow[t]{4}{*}{$\begin{array}{l}\text { Aile } \\
\text { Durumu*** }\end{array}$} & $\begin{array}{l}\text { Anne Baba } \\
\text { Boşanmış }\end{array}$ & $97,58 \pm 14,85$ & $35,00 \pm 6,04$ & $42,64 \pm 6,93$ \\
\hline & Anne Vefat & $83,66 \pm 17,92$ & $32,66 \pm 4,50$ & $41,00 \pm 5,29$ \\
\hline & Baba Vefat & $93,16 \pm 15,07$ & $40,00 \pm 8,00$ & $40,66 \pm 8,84$ \\
\hline & Anlamlılık & $\mathrm{KW}=1,506 ; \mathrm{p}=, 681$ & $\mathrm{KW}=3,805 ; \mathrm{p}=, 283$ & $\mathrm{KW}=5,128 ; \mathrm{p}=, 163$ \\
\hline \multirow{6}{*}{$\begin{array}{l}\text { Annenin } \\
\text { Öğrenim } \\
\text { Durumu }^{* * *}\end{array}$} & Okur yazar & $95,54 \pm 16,76$ & $36,86 \pm 8,07$ & $39,59 \pm 6,20$ \\
\hline & $\begin{array}{l}\text { değil } \\
\text { İlkokul }\end{array}$ & $93,38 \pm 15,89$ & $35,98 \pm 6,46$ & $38,65 \pm 7,33$ \\
\hline & IIKoKü & $95,48 \pm 16,99$ & $37,46 \pm 7,49$ & $40,29 \pm 8,00$ \\
\hline & Ortaokul & $98,10 \pm 12,38$ & $38,07 \pm 7,59$ & $41,28 \pm 8,50$ \\
\hline & $\begin{array}{l}\text { Lise } \\
\text { Üniversite }\end{array}$ & $103,16 \pm 15,81$ & $34,16 \pm 4,19$ & $36,66 \pm 4,73$ \\
\hline & Anlamlılık & $\mathrm{F}=1,673 \mathrm{p}=, 156$ & $\mathrm{~F}=1,371 ; \mathrm{p}=, 244$ & $\mathrm{~F}=1,620 ; \mathrm{p}=, 169$ \\
\hline Babanin & Okur yazar değil & $88,00 \pm 22,33$ & $33,33 \pm 7,57$ & $37,33 \pm 6,50$ \\
\hline Öğrenim & İlkokul & $94,32 \pm 15,48$ & $36,50 \pm 6,88$ & $38,88 \pm 6,89$ \\
\hline \multirow[t]{4}{*}{ Durumu $^{* * *}$} & Ortaokul & $93,50 \pm 17,54$ & $35,41 \pm 6,56$ & $38,58 \pm 7,64$ \\
\hline & Lise & $94,21 \pm 14,70$ & $38,10 \pm 7,60$ & $40,49 \pm 8,45$ \\
\hline & Üniversite & $100,42 \pm 14,90$ & $35,50 \pm 5,48$ & $39,35 \pm 7,39$ \\
\hline & Anlamlılık & $\mathrm{F}=1,573 ; \mathrm{p}=, 182$ & $\mathrm{~F}=1,710 ; \mathrm{p}=, 148$ & $\mathrm{~F}=0,721 ; \mathrm{p}=, 578$ \\
\hline Annenin & Tam Zamanlı & $96,51 \pm 18,47$ & $37,29 \pm 7,41$ & $38,92 \pm 8,03$ \\
\hline Çalışma & Yarı Zamanlı & $91,87 \pm 14,62$ & $35,62 \pm 6,19$ & $40,66 \pm 7,54$ \\
\hline \multirow[t]{2}{*}{ Durumu ${ }^{* * *}$} & Çalışmıyor & $94,90 \pm 15,43$ & $36,42 \pm 6,84$ & $39,14 \pm 7,39$ \\
\hline & Anlamlılık & $\mathrm{KW}=1,174 ; \mathrm{p}=, 556$ & $\mathrm{KW}=0,659 ; \mathrm{p}=, 719$ & $\mathrm{KW}=1,474 ; \mathrm{p}=, 478$ \\
\hline Babanın & Tam Zamanlı & $95,81 \pm 15,32$ & $36,76 \pm 6,90$ & $39,27 \pm 7,32$ \\
\hline Çalışma & Yarı Zamanlı & $92,30 \pm 16,62$ & $36,45 \pm 6,64$ & $40,19 \pm 8,08$ \\
\hline \multirow[t]{2}{*}{ Durumu $u^{* * * *}$} & Çalışmıyor & $93,82 \pm 16,60$ & $35,67 \pm 6,93$ & $38,53 \pm 7,60$ \\
\hline & Anlamlılık & $\mathrm{F}=1,042 ; \mathrm{p}=, 354$ & $\mathrm{~F}=0,633 ; \mathrm{p}=, 532$ & $\mathrm{~F}=0,635 ; \mathrm{p}=, 531$ \\
\hline
\end{tabular}

${ }^{*}$ testi ${ }^{* *}$ Mann Whitney-U test $i{ }^{* *}$ Kruskal Wallis test ${ }^{* * * *}$ One-way Anova test $i{ }^{*} p<0.05$ 
Tablo 4. Durumluk ve sürekli anksiyete puanları ile kariyer kararn yetkinlik beklentisi puanlarının öğrencilerin bazı sosyodemografik özellikleri ile ilişkisi $(\mathrm{N}=300)$

\begin{tabular}{|c|c|c|c|}
\hline & $\begin{array}{l}\text { Kariyer kararı yet- } \\
\text { kinlik beklentisi }\end{array}$ & $\begin{array}{l}\text { Durumluk } \\
\text { Anksiyete }\end{array}$ & $\begin{array}{l}\text { Sürekli } \\
\text { Anksiyete }\end{array}$ \\
\hline Yaş* & $\mathrm{r}=0,019 ; \mathrm{p}=, 738$ & $\mathrm{r}=0,132 ;{ }^{\ddagger} \mathrm{p}=, 022$ & $\mathrm{r}=-0,011 ; \mathrm{p}=, 849$ \\
\hline Anne yaşı* & $r=0,066 ; p=, 255$ & $\mathrm{r}=0,060 ; \mathrm{p}=, 298$ & $\mathrm{r}=0039 ; \mathrm{p}=, 504$ \\
\hline Baba yaşı* & $\mathrm{r}=0,080 ; \mathrm{p}=, 168$ & $\mathrm{r}=0,086 ; \mathrm{p}=, 136$ & $\mathrm{r}=0,022 ; \mathrm{p}=, 705$ \\
\hline $\begin{array}{l}\text { Ortalama kardeş sayısı } \\
\text { (kendisi dahil)* }\end{array}$ & $r=0,059 ; p=, 307$ & $\mathrm{r}=0,088 ; \mathrm{p}=, 129$ & $r=0,005 ; p=, 925$ \\
\hline Ortalama kaçıncı kardeş* & $\mathrm{r}=0,042 ; \mathrm{p}=, 466$ & $\mathrm{r}=0,090 ; \mathrm{p}=, 120$ & $\mathrm{r}=-0,003 ; \mathrm{p}=, 956$ \\
\hline
\end{tabular}

* Spearman korelasyon test $i^{\mp} p<, 05$

\section{Tartışma}

Bir meslek sahibi olma, mesleğini sürdürme ve mesleğini ilerletme yani kariyer yapma bireylerin hayatlarında alacakları en önemli kararlardan biridir. İşini severek yapmama, istenmeyen koşullarda çalışmak zorunda bırakılma, ağır iş yükü, çalışma saatlerinde belirsizlik ve uzun çalışma saatleri gibi nedenler özellikle hemşirelerin mesleki performansını olumsuz etkilemekte uzun vadede tükenmişliğe neden olmaktadır (Çatak ve Bahçecik, 2015). Bu nedenle mesleki kariyer yapma mesleğe başlamadan önce karar verilmesi gereken önemli bir süreçtir. Bu sürecin önemli bir karar aşaması olduğunun ancak üniversite son sınıfa yaklaştıkça bilincine varılmaktadır (Jung ve diğ., 2014; Kim, 2016).

Ülkemizde yapılan araştırmalarda hemşirelik öğrencilerinin kariyer kararı ve meslek seçimini etkileyen faktörler; demografik özellikler, mesleği isteyerek ya da başka birinin yönlendirmesi ile seçme, kolay iş bulabilme düşüncesi olarak bildirilmektedir (Özdelikara ve diğ., 2016; Özdemir ve Şahin, 2016; Temel ve diğ., 2018). Ayrıca bu araştırmaların çoğunlukla hemşirelik bölümüne yeni başlayan birinci sınıf öğrencileri ile yapıldığı görülmektedir (Özdelikara ve diğ., 2016; Özdemir ve Şahin, 2016). Oysaki üniversite üçüncü ve son sınıf öğrencisi olmak iş hayatına atılmak için son aşamadır ve öğrencilerin geleceğe dair kaygılarını daha yoğun olarak hissettikleri dönemdir. Çünkü artık çocukluktan çıkılacak ve yetişkinliğe adım atılacaktır. Öğrenciler gerçek hayatla yüzleşmek zorunda kalacaklar ve sorumluluk sahibi olacaktır. Bu dönemde anksiyete ve stres düzeyinin yüksek olması sağlıklı düşünmeyi olumsuz etkileyeceği için bi- 
reylerin yanlış karar vermesine ve kariyeri ile ilgili umutsuzluğa kapılmasina neden olabilmektedir (Gümüştekin ve Gültekin, 2009). Bu düşünceyi destekler nitelikte araştırma kapsamına alınan 4.sınıfta okuyan hemşirelik öğrencilerinin 3.sınıfta okuyan öğrencilere göre daha yüksek düzeyde anksiyete yaşadığı tespit edilmiştir.

Kim ve ark.(2015) 147 hemşirelik öğrencisi ile yaptıkları çalışmada; öğrencilerin mutluluğu üzerinde kariyer kararı yetkinlik beklentisinin etkili olduğu bildirilmektedir. Çünkü mesleğini seven ve onu sürdürebileceğini düşünen öğrencilerin geleceğe daha umutla baktığ1 düşünülmektedir. Choi ve Jung (2018) ise dört farklı üniversitede son sinıfta okuyan 300 hemşirelik öğrencisi ile yaptıkları çalışmada, öğrencilerin kariyer yapma yetkinlik beklentisinin iş bulma ve iş hayatına atılmadaki stresi azaltmada etkisi olduğunu bildirmektedir. Çünkü öğrencilerde kariyer yapma kararı beklentisi arttıkça kariyer arama davranışının arttığı da bildirilmektedir (Lee ve Kim, 2015). Ancak bu araştırmada öğrencilerin anksiyetesi arttıkça kariyer kararı beklentisinin de arttığı tespit edilmiştir. Bu bulgu ile literatüre zıt bir sonuç elde edilmiştir. Aslında anksiyetesi yüksek hemşirelik öğrencilerin daha umutsuz olduğu yapılan araştırmalarda gösterilmiştir (Sevinç ve Özdemir, 2017; Taslak ve Işıkay, 2015). Ancak yüksek anksiyetenin öğrencileri alert durumuna getirerek onların çok çalışmasına ve gelecekleri adına kariyer planları yapmasına teşvik ettiği düşünülmektedir.

Araştırma kapsamına alınan hemşirelik öğrencilerinin anksiyete nedenlerine bakıldığında; cinsiyete faktörü göz önüne alındığında erkek öğrencilerin daha fazla anksiyete yaşadığı görülmüştür. Kahraman ve ark.(2015) 17 erkek hemşirelik öğrencisi ile derinlemesine görüşme yaptıkları araştırmada; öğrencilerin ekonomik kaygılar nedeni ile hemşirelik mesleğini tercih ettiği ve mesleği ağırlıklı olarak kadınların yapabileceği bir meslek olarak gördüklerini belirttiği bildirilmektedir. Ayrıca aynı çalişmada erkek öğrenciler, güç gerektiren durumlarda erkek hemşirelerin yararlı olacağını düşündüklerini ifade ettiği belirtilmektedir. Görülüyor ki erkek hemşirelik öğrencisi ve erkek hemşire sayısının gün geçtikçe artması, günümüzde "hemşirelik, kadın mesleğidir" bakış açısını hala tam olarak yıkamamıştır. Bu bakış açısını hemşirelik mesleğini seçtikleri halde kendilerinin de aşamadığı görülmektedir. Kaldı ki Kahraman ve ark. (2015) erkek öğrencilerin çoğunun kolay iş bulma düşüncesi ile hemşireliği seçtiği belirtilmektedir. Erkek hemşirelik öğrencilerinin özellikle kız 
akranlarıyla klinikte ve sınıf içi performansta kendilerini baskıladıklarını ve klinikten dışlanacaklarını düşündükleri için eğitim ortamında ve kliniklerde rahatsız hissettiği bildirilmektedir (Abdal, Masoudi Alavi, ve Adib-Hajbaghery, 2015; Anderson, 2014). Gerek öğrenciyken kliniklerde yaşanan gerekse de iş hayatında yaşanacağını düşündükleri sıkıntılar nedeniyle erkek hemşirelik öğrencilerinin daha fazla anksiyete yaşadıkları düşünülmektedir.

$\mathrm{Bu}$ araştırmada, öğrencilerin yaşı arttıkça durumluluk anksiyetesinin de arttı̆̆ görülmüştür. Üniversite öğrencileri mezun olduktan sonra hayat ile ilgili bağımsız karar ve birçok konuda sorumluluk almak zorunda kalacaktır. Genel olarak hayat ile baş edebilmek ve sorumluluklarının üstesinden gelebilmek için öğrencilerin kariyeri yani iş hayatı büyük önem taşımaktadır. Çünkü öğrenciler hayatlarını kariyerleri doğrultusunda şekillendirecektir. Bu düşüncelerin farkına varmak ancak yaşla beraber gelecek olgunlukla mümkündür. Bu nedenle öğrencilerin yaşları arttıkça anksiyete düzeylerinin de arttığı düşünülmektedir.

\section{Sonuç}

Elde edilen bulgular doğrultusunda, hemşirelik öğrencilerinin durumluk ve sürekli anksiyete düzeyi kariyer kararı yetkinlik beklentisini etkilemektedir. Öğrencilerin anksiyetesi arttıkça kariyer kararı yetkinlik beklentisinin de arttığ1 görülmüştür. Bunun yanı sıra öğrencilerin cinsiyet, yaş, sınıfına göre anksiyete düzeylerinin de değiştiği tespit edilmiştir. Öğrencilerin kariyer kararını ve anksiyetesini etkileyen nedenlerin incelendiği çalışmalar ile durum tespiti yapılarak öğrencilerin kariyer kararı beklentisinin yükseltilmesi ve anksiyetesinin azaltılması adına olumlu ve etkili müdahaleler yapılabileceği düşünülmektedir. Böylece mesleğe atılan ve mesleği yüceltmek adına güzel işler yapacak hemşirelerin yetişeceği düşünülmektedir. Bu nedenle hemşirelik öğrencilerinde anksiyeteye neden olan faktörlerin belirlenmesine ve anksiyete ile kariyer yetkinlik beklentisi arasındaki ilişkiyi tanımlamaya yönelik daha fazla sayıda çalışma yapılması önerilmektedir. 


\title{
EXTENDED ABSTRACT
}

\section{Determining The Effect of Anxiety Status on Career Decision Self Efficacy in Nursing Students}

\author{
Meltem Kürtüncü - Hicran Yıldız - Aylin Kurt \\ Zonguldak Bülent Ecevit University, Uludă̆ University
}

Career decision is one of the most important decisions that individuals can make throughout their life, as all decisions they take on subjects such as making a career and shaping this career process will affect their whole life. This decision affects both the professional performance and the job satisfaction in the future. Especially having career goals and deciding on career are effective on occupational burnout. In the long term, individuals who experience constant anxiety and stress will be affected by the happiness of life. Therefore, the decision to make a career can become a painful process that creates stress for individuals. Nowadays, career is a decision that individuals have to make at the stage of transition from student to business life in the last year of university.

Senior students are required to collect information about the career options in front of their profession and to evaluate them and make plans for the future. Especially nowadays, the number of nursing students at undergraduate level is increasing. This situation may cause the quality of the education received by the students to decrease and not to find a job after graduation and / or to work in undesirable conditions and positions. Not knowing what to do after graduation is one of the reasons for concern about the careers of nursing students who are approaching graduation. In addition, negative experiences experienced by students during the education period negatively affect career thinking, process and expectations of the future.

In the literatüre, the factors effected the career decision of nursing students were the descriptive characteristics such as gender, class, age and financial situation such as gender, class, age and financial situation, and the profession by choosing one by one or another, and the job satisfaction in our country. In addition, thosestudies were mostly researched in nursing first year students and the reasons why they chosen. However, being 
a third and fourth year student at the university is the final stage for getting into business life, and the periods during which students feel more anxious about the future. The high level of anxiety and stress may cause healthy thinking to negatively affect individuals and make their career hopeless. When we look at the studies conducted in our country, we did not find any study investigating the effect of anxiety status of nursing students on career decision.

This study aimed to determine the effect of anxiety on nursing students' career decision competence expectancy.

- What is the level of anxiety expectation of career decision competence among nursing students?

- Do nursing department students' career decision competency expectations differ according to their sociodemographic characteristics?

- Is there a relationship between anxiety expectancy and career decision competency expectation among nursing students?

The sample of the descriptive and analytical study consisted of 300 students in the 3rd and 4th year nursing department in 2017-2018. The data were obtained by "Questionnaire Form", "State of Anxiety and State Anxiety Scale" and "Career Decision Competency Expectation Scale". Data was evaluated by percentages, averages, $t$ test, Mann Whitney $U$ test, Kruskal Wallis test, One-way Anova test, Pearson and Spearman correlation test.

$77,7 \%$ of the students with a mean age of $22,03 \pm 1,46$ were women. $60,7 \%$ of the students are 3 rd grade and $39,3 \%$ are 4 th grade. $47,7 \%$ of the students stay in the dormitory. The mean age of the mothers of the students was $47,35 \pm 5,42$ and their fathers were $51,29 \pm 5,79.60 \%$ of the mothers of the students and $42 \%$ of their fathers are primary school graduates. $13,7 \%$ of the mothers and $63,7 \%$ of their fathers work full time. $91,3 \%$ of the students are together with their parents. $30 \%$ of the students are $2,30 \%$ are $3,19,7 \%$ are 4 brothers $43,3 \%$ of the students were first children.

The mean score of state anxiety score of the students is $36,48 \pm 6,86$, continuous anxiety is $39,24 \pm 7,48$ and career decision is $94,88 \pm 15,80$. A significant relationship was found between the state and trait anxiety scores of the students and the career expectancy score $(p<, 05)$. Significant 
correlations were found in state anxiety scores of the students according to age, gender and class $(\mathrm{p}<, 05)$.

In line with the findings, nursing students' level of state and trait anxiety affects career expectancy competence expectancy. It was observed that career expectancy and competence expectancy increased as the students' discomfort increased.In addition, it was determined that the anxiety levels of students according to gender, age and class also changed.It is thought that positive and effective interventions will be made in order to increase the expectation of career decision of the students and decrease anxiety.Thus, it is thought that the nurses who will be employed in the profession and will do jobs in order to glorify the profession.For this reason, it is recommended that more studies should be done to determine the factors causing anxiety in nursing students and to define the relationship between anxiety and career expectancy expectations.

\section{Kaynakça / References}

Abdal, M., Masoudi Alavi, N. ve Adib-Hajbaghery, M. (2015). Clinical selfefficacy in senior nursing students: A mixed- methods study. Nursing and Midwifery Studies, 4(3), 15-22. http://doi.org/10.17795/nmsjournal29143

Anderson, J. A. (2014). Understanding male nursing student perceptions of the influence of gender: a qualitative case study approach of students, faculty, and administration in a Pacific Northwest nursing Program. Doctoral thesis, ProQuest. (UMI Number: 3636207)

Choi, H. J. ve Jung, K. I. (2018). Moderating effects of career decision-making self-efficacy and social support in the relationship between career barriers and job-seeking stress among nursing students preparing for employment. J Korean Acad Nurs Adm, 24(1), 61-72.

Çaparlar C.Ö. ve Dönmez, A. (2016). Bilimsel araştırma nedir, nasıl yapılır? Turk J Anaesthesiol Reanim. 44, 212-218. http://doi.org/ 10.5152/TJAR. 2016.34711

Çatak, T. ve Bahçecik, N. (2015). Hemşirelerin iş yaşamı kalitesi ve etkileyen faktörlerin belirlenmesi. MÜSBED, 5(2), 85-95. http://doi.org/10.5455/ musbed.20150309010354

Gümüştekin, G. E. ve Gültekin, F. (2009). Stres kaynaklarının kariyer yönetimine etkileri. Dumlupınar Üniversitesi Sosyal Bilimler Dergisi, 23, 147158. 
Işık, E. (2010). Sosyal bilişsel kariyer teorisi temelli bir grup müdahalesinin üniversite öğrencilerinin kariyer kararı yetkinlik ve mesleki sonuç beklenti düzeylerine etkisi. Doktora tezi, YÖK Tez Merkezi. (Tez no: 294402).

Jung, J. S., Jeong, M. J. ve Yoo, I. Y. (2014). Relations between satisfaction in major, career decision-making self-efficacy and career identity of nursing students. J Korean Acad Soc Nurs Educ, 20(1), 27-36.

Kahraman, A. B., Ozansoy Tunçdemir, N. ve Özcan, A. (2015). Toplumsal cïnsïyet bağlamında hemşïrelik bölümünde öğrenïm gören erkek öğrencilerïn mesleğe yönelik algıları. Sosyoloji Araştırmaları Dergisi, 18(2), 108-144. http://doi.org/10.18490/sad.58405

Karasar, N. (2013). Bilimsel araştırma yöntemi. Ankara: Nobel Yayın Dağıtım.

Kılıç, H. F. (2018). Hemşirelik öğrencilerinin eğitim stresi ve mesleki benlik saygısı arasındaki ilişki. HUHEMFAD-JOHUFON, 5(1), 49-59.

Kim, S., ve Lee, S. (2015). The influence of job-seeking stress, career decisionmaking self-efficacy, self-esteem and academic achievement on nursing students' happiness. Korean J Adult Nurs, 27(1), 63-72. http://doi.org/10.7475/kjan.2015.27.1.63

Kim, S.O. (2016). The relationship among self-efficacy, career decision making types and career decision level of nursing students. J Korean Acad Soc Nurs Educ, 22(2), 210-219.

Kocaman, G. ve Yürümezoğlu, H. A. (2015). Türkiye'de hemşirelik eğitiminin durum analizi: Sayılarla hemşirelik eğitimi (1996-2015). Yüksek Öğretim ve Bilim Dergisi, 5(3), 255-262. http://doi.org/10.5961/jhes.2015.127

Lee, K. A. ve Kim, J. (2015). Nursing students' awareness of career decisionmaking self-efficacy, career search behavior and commitment to career choice. Perspectives in Nursing Science, 12(1), 42-49.

Önel, N. ve LeCompte, A. (1983). Durumluk - sürekli kaygı envanter el kitabı (1st ed.). İstanbul: Boğaziçi Üniversitesi Yayınları.

Özdelikara, A., Ağaçdiken, S. ve Aydın, E. (2016). Hemşirelik öğrencilerinin meslek seçimi ve etkileyen faktörler. ACU Sağllk Bil Derg, 2, 83-88.

Özdemir, F. K. ve Şahin, Z. A. (2016). Hemşirelik bölümü birinci sınıf öğrencilerinin meslek seçimini etkileyen faktörler. ACU Sağlık Bil Derg, 1, 28-32.

Sevinç, S. ve Özdemir, S. (2017). Hemşirelik öğrencilerinin kaygı ve umutsuzluk ilişkisi: Kilis örneği. HEMAR-G, 19(2), 14-24. 
Taslak, S. ve Işıkay, Ç. (2015). Hemşirelik bölümü öğrencilerinin eğitim alg1ları ile kaygı ve umutsuzluk düzeylerine yönelik bir araştırma: Sağlık yüksekokulu örneği. SDÜ Sağlık Bilimleri Enstitüsü Dergisi, 6(3), 108115.

Temel, M., Bilgic, S. ve Celikkalp, U. (2018). Hemşirelik öğrencilerinin meslek seçiminde etkili faktörler. Yüksek Öğretim ve Bilim Dergisi, 8(3), 480487. http://doi.org/10.5961/jhes.2018.289

\section{Kaynakça Bilgisi / Citation Information}

Kürtüncü, M., Yıldız, H. ve Kurt, A. (2019). Hemşirelik bölümü öğrencilerinde anksiyete durumunun kariyer kararı yetkinlik beklentisine etkisinin belirlenmesi. OPUS-Uluslararası Toplum Araştırmaları Dergisi , 14(20), 223-238. DOI: 10.26466-/opus.581800 